\title{
Extraction and purification of formonometin from Trifolium pratense L: Physicochemical properties of its complex with lecithin
}

\author{
Korbanjhon Brad ${ }^{1}$, Yan Zhang ${ }^{2 \star}$ and Jie Gao ${ }^{2}$ \\ ${ }^{1}$ College of Chemistry and Environmental Sciences, Yili Normal University, Yining, 835000, ${ }^{2}$ Key Laboratory of Food Nutrition \\ and Safety, Tianjin University of Science and Technology, Ministry of Education, Tianjin 300457, China \\ *For correspondence: Email: cpzyyan@126.com; Tel: +8613752353154
}

Sent for review: 5 April 2017

Revised accepted: 23 July 2017

\begin{abstract}
Purpose: To isolate formononetin from Trifolium pratense L. (red clover), prepare its complex with lecithin foe enhanced solubility and evaluate its physicochemical properties.

Methods: Formononetin was extracted from red clover. The complex of formononetin with lecithin was prepared by solvent method in a ratio of 2.5:1.0 (lecithin : formononetin). The physicochemical properties of the complex were investigated by ultraviolet-visible spectrometry (UV/Vis), Fourier transform infrared spectroscopy (FT-IR), scanning electron microscopy (SEM), differential scanning calorimetry (DSC) and $x$-ray diffractometry (XRD).

Results: UV data showed that there was no significant difference $(p<0.05)$ between the peak intensity of the physical mixture and the complex, while FT-IR analysis indicated interaction between formononetin and lecithin. SEM showed that formononetin was successfully integrated in the structure of lecithin. DSC thermograms of the complex mainly demonstrated that the presence of lecithin caused the disappearing of characteristic endothermal peaks of formononetin, while $x$-diffractograms indicate that the crystalline peak of formononetin was absent in the complex.

Conclusion: The complex formed is held together by non-covalent-bonds and thus demonstrates new physical and chemical characteristics.
\end{abstract}

Keywords: Formononetin, Lecithin, Complex, Physicochemical characteristics

Tropical Journal of Pharmaceutical Research is indexed by Science Citation Index (SciSearch), Scopus, International Pharmaceutical Abstract, Chemical Abstracts, Embase, Index Copernicus, EBSCO, African Index Medicus, JournalSeek, Journal Citation Reports/Science Edition, Directory of Open Access Journals (DOAJ), African Journal Online, Bioline International, Open-J-Gate and Pharmacy Abstracts

\section{INTRODUCTION}

Red clover (Trifolium pratense L.), one of several botanical dietary supplements, has been medically used in the alleviation of hot flashes and other menopausal symptoms [1]. Commercial extracts of red clover contain is mainly made up of four compounds. They are mildly estrogenic genistein, isoflavones daidzein, biochanin A and formononetin [2]. Since isoflavones, one of the four compounds it contained can be used as a natural replacement of estrogen, it is popular for its function to alleviate climateric symptoms in older women.

Formononetin (7-Hydroxy-4'-methoxyisoflavone, $\mathrm{C}_{16} \mathrm{H}_{12} \mathrm{O}_{4}, \mathrm{CAS}:$ 485-72-3, MW: 268.3), one of the major substance in Red clover, has become a focus of study due to its various pharmacological and biological activities, such as anti-tumor [3], anti-oxidant [4], anti-bacterial [5], anti-inflammatory [6], anti-atherosclerosis [7], and anti-osteoporosis [8]. Therefore, it is widely used as an additive in the food and pharmaceutical industries. Formononetin is 
usually extracted from natural plants by organic solvents $[9,10,11]$. For structure and chemical analysis, formononetin of high purity can be obtained by further purification. The most frequently used purification method in the industrial manufacture is crystallization. This is the key process to guarantee the purity and yield of formononetin [12]. Studies indicate that formononetin from Trifolium pratense L. (red clover) processes excellent activity to scavenge free radicals and that its administration can enhance the tissue enzymatic and nonenzymatic defenses of mice and thus prevent the lipid peroxidation formation [13].

Although formononetin possesses these numerous beneficial activity, its application has been limited by the poor solubility in water. Solubility is essential in the oral bio-availability of functional food and drugs, since low solubility leads to the poor permeability of intestinal epithemlial cells and thus decrease its gastrointestinal absorption.

Lecithin has been used as an ingredient in food, cosmetic and pharmaceutical products. Reports showed that Lecithin extracted from soybeans is biocompatible [14] and that it plays an important part in various functions such as memory, transmembrane signaling, metabolism [15], cardiovascular health, cognitive and liver function, physical and athletic performance. It has also been used for transdermal drug delivery [16]. In recent years, with its ability to selfassembles at the oil-water interface in various approaches such as micro emulsion [17], hydrogels [14,16], micelles [18], liposomes [1922], this commonly used zwitterionic phospholipid surfactant has been used as a carrier for many active ingredients with low solubility to increase their bio-availability.

In the present study, in order to increase the solubility and bio-availability of formononetin, lecithin has been used for the first time to interact with formononetin. Firstly, chemical method was used to synthesis the compound of lecithin formononetin (SLF). Then a combination of methods such as UV, IR, SEM, DSC and XRD is used to study the characteristic of SLF.

\section{EXPERIMENTAL}

\section{Materials}

Red clover (Trifolium pratense L.) was collected in Yili, Xinjiang, China in September 2015. The material was authenticated by Prof Korbanjhon Brad of Yili Normal University (The School of Chemistry and Environmental Engineering). A voucher specimen (no. YLNU2015091401) was kept in the herbarium of the university. Lecithin was offered by Sangon Biotech. All the agents used in the following experiment were of analytically pure.

\section{Extraction of formononetin}

Dried red clover (Trifolium pratense L.) from were crushed into powder before being soaked in 5 volumes of $90 \%$ methanol for $24 \mathrm{~h}$ and then boiled under reflux for $4 \mathrm{~h}$. Repeat the process for two more times. After cooling, filter the extract. Then the extract was filtered using filter paper after cooling. The filtrate was extracted by acetic ether. Then after the acetic ether was removed, the extraction was refluxed by $6 \mathrm{~mol} / \mathrm{L}$ $\mathrm{HCl}$. The extraction was concentrated by rotary evaporation to obtain crystal. The crystal was recrystallized in $95 \%$ methanol for two more times. Afterward, the purified crystal was dried to obtain a kind of white powder.

\section{Identification of formononetin}

UV, FT-IR, NMR, mass spectrometry (MS) and DSC analysis were conducted to identify the obtained formononetin.

\section{Synthesis of lecithin-formononetin complex (SLF)}

Tetrahydrofuran $(50 \mathrm{~mL})$ was used to disolve 100 $\mathrm{mg}$ of formononetin and $250 \mathrm{mg}$ of soy lecithin by magnetic stir at $25{ }^{\circ} \mathrm{C}$ for $4 \mathrm{~h}$. Then they were filtrated by filtrate paper. Then the SLF was obtained after the solvent was removed.

\section{Preparation of physical mixture of lecithin and formononetin (PMSLF)}

$100 \mathrm{mg}$ of formononetin were fully mixed with $250 \mathrm{mg}$ of lecithin to obtain the physical mixture.

\section{UV, FT-IR and NMR analyses}

Methanol $(10 \mathrm{~mL})$ was used to dissolve $1 \mathrm{mg}$ of soy lecithin, formononetin, SLF, PMSLF respectively to conduct the UV spectra analysis. The wavelength was set ranging from 220 to 500 $\mathrm{nm}$. The type of scanning UV spectrophotometer was UV-2500PC, Shimadzu, Japan.

The sample for FT-IR analysis was prepared by a tablet prepared by the crushed powder of $1 \mathrm{mg}$ of sample and $150 \mathrm{mg}$ of dried $\mathrm{KBr}$. The type of Fourier transformed IR spectrophotometer is VECTOR22, Bruker, Germany. The wavelength was set ranging from 4000 to $500 \mathrm{~cm}^{-1}$ [23]. 
OPUS software (Bruker Germany) was used to process the recorded data.

A Bruker spectrometer $(400 \mathrm{MHz})$ at a probe temperature of $298 \mathrm{~K}$ was used to record the 13C NMR spectra and $1 \mathrm{H}$ spectra [24].

\section{Scanning electron microscopy (SEM)}

A copper testing stub was used as the carrier of the samples. A layer of gold was sputtered on them before testing. Under $10 \mathrm{kV}$ and low vacuum, the micrographs were obtained. The micro-structure of samples was observed by a SU1510 (Hitachi, Japan) scanning electron microscope [25].

\section{Differential scanning calorimetry (DSC)}

The temperature was increased at the speed of $10{ }^{\circ} \mathrm{C} / \mathrm{min}$ from 30 to $300{ }^{\circ} \mathrm{C}$ under the protection of nitrogen. The DSC equipment model was DSC60, Shimadzu, Japan. An in-built software (Shimadzu, Japan) was used to process the recorded data.

\section{X-ray diffractometry (XRD)}

A D8 Advance X ray diffractometer (XRD - 6100, Shimadzu, Japan) was used to generate monochromatic $\mathrm{Cu} \mathrm{Ka}$ radiation (wavelength = $1.54056 \mathrm{~A}^{\circ}$ ). $40 \mathrm{kV}$ was set as the tube voltage, while $40 \mathrm{~mA}$ was set as the tube current. The scanning regions of the diffraction angle $(2 \theta)$ were set between $5-70{ }^{\circ} \mathrm{C}$ with the scanning speed of $4{ }^{\circ} \mathrm{C} / \mathrm{min}$.

\section{RESULTS}

\section{Structural characteristics of complex}

Property: White acicular crystal (methanol); m.p. $257 \sim 258{ }^{\circ} \mathrm{C}$; UV $\lambda \max (\mathrm{nm}): 244 、 328$; IR $\left(\mathrm{kBr}, \mathrm{v}_{\max }, \mathrm{cm}^{-1}\right): 3148(-\mathrm{OH}), 1640$ (conjugated $\mathrm{C}=\mathrm{O}), 1610,1570,1515(-\mathrm{Ar}), 2980,2835,1445$, 1385(-CH3)ESI-MS m/z:269 [M + H] +。 ESIMS m/z: $291.1[\mathrm{M}+\mathrm{Na}]+, 267.0$ [M]- ; 1H-NMR (DMSOd6, $400 \mathrm{MHz}) \delta: 10.80(1 \mathrm{H}$, br s, $-\mathrm{OH})$ , $8.33(1 \mathrm{H}, \mathrm{s}, \mathrm{H}-2), 7.97(1 \mathrm{H}, \mathrm{d}, \mathrm{J}=8.8 \mathrm{~Hz}$ $\mathrm{H}-5), \quad 7.50\left(2 \mathrm{H}, \mathrm{d}, \mathrm{J}=8.7 \mathrm{~Hz}, \mathrm{H}-2^{\prime}, \mathrm{H}-6^{\prime}\right)$ $6.96\left(2 \mathrm{H}, \mathrm{d}, \mathrm{J}=8.7 \mathrm{~Hz}, \mathrm{H}-3^{\prime}, \mathrm{H}-5^{\prime}\right), 6.94$ $(1 \mathrm{H}, \mathrm{dd}, \mathrm{J}=8.8,2.2 \mathrm{~Hz}, \mathrm{H}-6), 6.87(1 \mathrm{H}, \mathrm{d}$ , J=2.2 Hz, H-8), $3.78(3 \mathrm{H}, \mathrm{s}, \mathrm{OCH} 3) .13 \mathrm{C}-$ NMR (DMSO-d6, $100 \mathrm{MHz}$ ) ס: 174.6 (C-4 ), 162.6 (C-7), $159.0\left(\mathrm{C}-4^{\prime}\right), 157.5$ (C-9) , 153.2 (C-2), 130.1 (C-2'), 130.1 (C-6'), 127.3 (C-5), 124.2 (C-1'), 123.2( C-3), 116.6 (C-10), 115.2 (C-6 ), 113.6(C-3'), 113.6 (C-5'), 102.1 ( C-8)
55.1 ( 4'-OCH3). The spectral data confirmed the identity of the substance as the isoflavone, formononetin $[26,27]$.

\section{Spectra analyses}

Figure 1 showed the UV spectra of lecithin, formononetin, SLF, PMSLF. The spectrum of SLF and PMSLF were quite similar. Characteristic absorption peaks were observed at 244 and $328 \mathrm{~nm}$ in both of the two samples. This suggested that the functional groups that cause these absorption peaks remained unchanged. As shown in Figure 2, the characteristic absorption peaks of both lecithin and formononetin could be observed in the figure of PMSLF and that the only change is the intensity of these peaks. This suggested that the change was resulted from the pilling up effect of lecithin and formononetin. By the contrast, significant changes were observed at the characteristic absorption peaks of $-\mathrm{OH}$ and $\mathrm{C}=\mathrm{O}$. This suggested that these functional groups of formononetin had been interacted with lecithin's. Although absorption peak was also observed at $1733 \mathrm{~cm}-1$ in SLF, changes were observed in the shape, width and intensity. This showed that the structure of lecithin was also affected by formonoetin.

\section{Morphology}

Figure 3 presented the SEM images of formononetin, lecithin, SLF and PMSLF, the surface of lecithin showed irregular structures of crumbs accumulation and intertwining. It indicated that the molecule of lecithin were easily curled to form a variety of irregular shapes. By contrast, formononoetin appeared as irregularly shaped crystals; PMSLF sample showed the morphology of lecithin and formononetin simply mixed together. The SEM image of SLF different from the three showed that formononetin seemed to incubate in the structure of lecithin.

\section{Thermal characteristics}

The DSC features of the four samples were presented in Figure 4. An endothermal peak (onset temperature at around $260^{\circ} \mathrm{C}$ ) was at this temperature that formononetin. This is the starting temperature for the melting of formononetin. Since lecithin is a kind of amorphous material without a certain melting point, no obvious endothermal peak was observed. The endothermal peak of formononetin was disappeared in the thermograms of SLF and PMSLF, since the thermograms of formononetin was pilled by that of lecithin. 


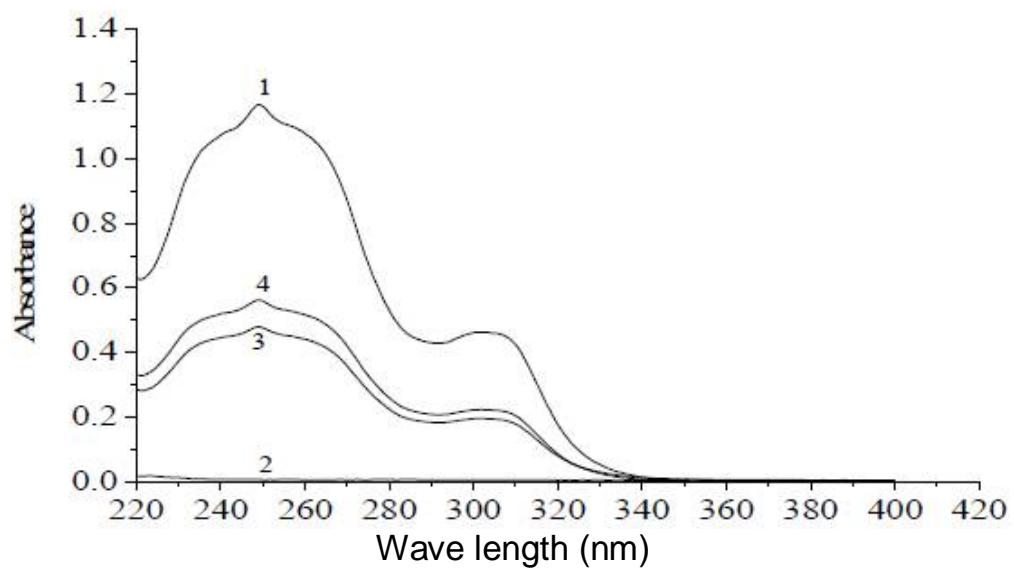

Figure 1: UV spectra of lecithin (2), formononetin (1),their physical mixture (3) and complex (4)

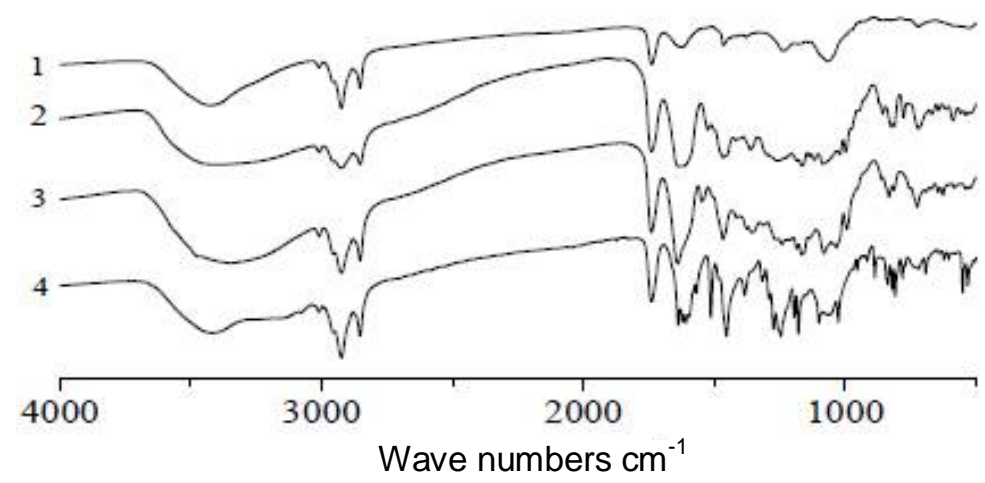

Figure 2: IR spectra of lecithin (1), formononetin (4), their physical mixture (2) and complex (3)

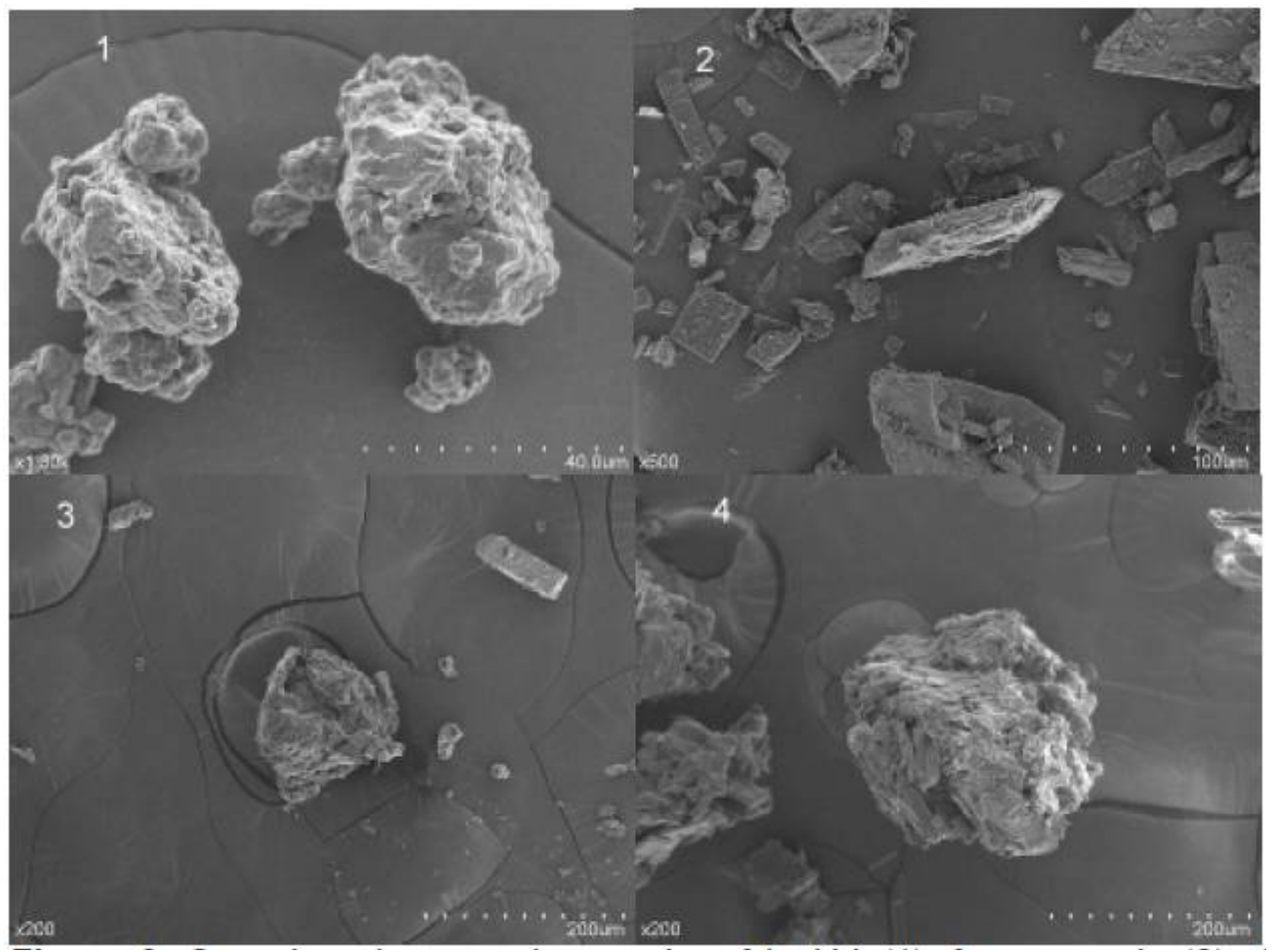

Figure 3: Scanning electron micrographs of lecithin(1), formononetin (2), their physical mixture (3) and complex (4) 


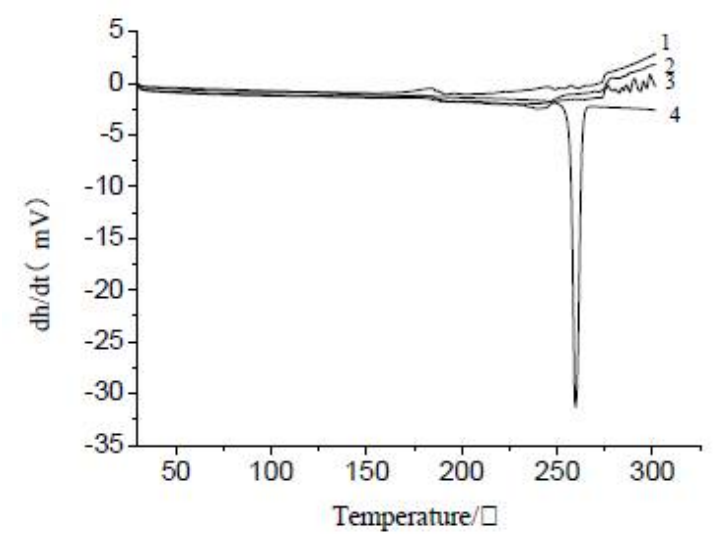

Figure 4: DSC curves of lecithin (1), formononetin (4), their physical mixture (2) and complex (3)

\section{X-diffractograms}

The powder X-ray diffraction patterns of lecithin, formononetin, SLF and PMSLF were shown in Figure 5. The presence of crystalline organic molecule was indicated by the sharp crystalline peaks indicating the presence of crystalline organic molecule in the powder diffraction pattern of formononetin [28]. Meanwhile, the diffraction pattern of lecithin showed amorphous property with no indication of crystalline peaks. Affected by the containing of lecithin, intensity of peaks in the PMSLF was subdued, while the peaks were completely disappeared in the PMSLF.

\section{DISCUSSION}

Formononetin of high purity in the form of white crystal was obtained by solvent extraction, refluxing and recrystallization. Various methods such as NMR, Mass spectrometry, UV and DSC analyses were used to identify the white crystal to be formononetin.

The optimum ratio of formononetin to lecithin for the formation of SLF was $1: 2.5(\mathrm{~m} / \mathrm{m})$. SLF showed better solubility in comparing to formononetin. Its UV data indicated that it contained the groups that caused some characteristic absorption peaks of formononetin. Judging from significant changes observed in the FT-IR spectrum, several functional groups of formononetin had been interated with lecithin's.

SEM indicates that formononetin was successfully integrated in lecithin in SLF.

The thermogram of formononetin showed an endothermal peak. Since lecithin is a kind of amorphous material without a certain melting point, no obvious endothermal peak was observed. No obvious endothermal peak was
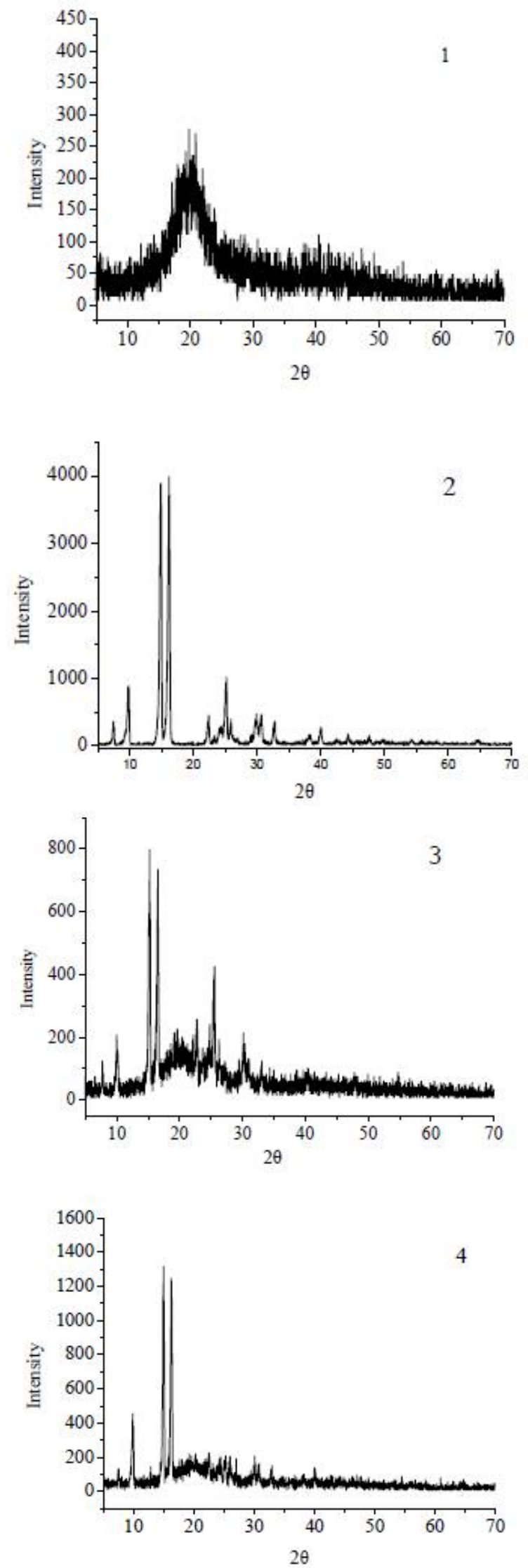

Figure 5: X-ray diffraction patterns of lecithin (1), formononetin (2), their physical mixture (3) and complex(4)

Trop J Pharm Res, August 2017; 16(8): 1761 
observed in the PMSLF, while the peak disappeared in SLF.

In the XRD analysis, the presence of crystalline organic molecule was indicated by sharp crystalline peaks in the powder diffraction pattern of formononetin. Meanwhile, the crystalline peaks were not presented in the diffraction pattern of lecithin. Affected by the presence of lecithin, the intensity of peaks in the PMSLF was subdued, while the peaks completely disappeared in SLF. This may be caused by the directional polarity end connection of formononetin and lecithin which resulted to the high disparity of the PMSLF molecule and thus displayed a kind of amorphous state. Since the arrangement of amorphous material molecules are more irregular, the free energy is higher, the solubility and dissolution rate is better. This may also be the reason why the solubility of phospholipid complex are better compared with the original crystal materials.

\section{CONCLUSION}

The lipophilic solubility of formononetin is significantly enhanced by complexation with lecithin. This is probably due to the fact that formononetin is complexed with lecithin by linkage of several functional groups. The high polarity of lecithin resulted in the higher solubility of the complex in water. The characteristics of SLF are different from those of PMSLF, lecithin and formononetin. Thus, application of formononetin may be enhanced by complexation with lecithin.

\section{DECLARATIONS}

\section{Acknowledgement}

The financial support provided by National Science Foundation of China (no. 31401663) is greatly appreciated.

\section{Conflict of Interest}

No conflict of interest associated with this work.

\section{Contribution of Authors}

The authors declare that this work was done by the authors named in this article and all liabilities pertaining to claims relating to the content of this article will be borne by them.

\section{Open Access}

This is an Open Access article that uses a fund- ing model which does not charge readers or their institutions for access and distributed under the terms of the Creative Commons Attribution License (http://creativecommons.org/licenses/by/ 4.0) and the Budapest Open Access Initiative (http://www.budapestopenaccessinitiative.org/rea d), which permit unrestricted use, distribution, and reproduction in any medium, provided the original work is properly credited.

\section{REFERENCES}

1. Coon JT, Pittler MH, Ernst E. Trifolium pratense isoflavones in the treatment of menopausal hot flushes: a systematic review and meta-analysis. Phytomedicine 2007; 14: 153-159.

2. Rull Prous S, Arias C. Process of preparation of plant extracts with high isoflavone content. European Patent 2008; EP1391208.

3. Xin $D, X u W$, Sikes $R A, W u$ C. Combination of low dose of genistein and daidzein has synergistic preventive effects on isogenic human prostate cancer cells when compared with individual soy isoflavone. Food Chem 2013; 141: 1923-1933.

4. Kayano SI, Matsumura $Y$, Kitagawa $Y$, Kobayashi $M$, Nagayama $A$, Kawabata $N$, Kikuzaki $H$, Kitada $Y$. Isoflavone $C$-glycosides isolated from the root of kudzu (Pueraria lobata) and their estrogenic activities. Food Chem 2012; 134:282-287.

5. Das Neves MV, Da ST, Lima EO, Da CE, Oliveira EJ. Isoflavone formononetin from red propolis acts as a fungicide against Candida sp. Braz J Microbiol 2016; 47: 159-166.

6. Jin SE, You KS, Min BS, Jung HA, Choi JS. Antiinflammatory and antioxidant activities of constituents isolated from Pueraria lobata roots. Arch Pharm Res 2012; 35: 823-837.

7. Mahesha $H$, Singh $S$, Rao A. Inhibition of lipoxygenase by soy isoflavones: evidence of isoflavones as redox inhibitors. Arch Biochem Biophys 2007; 461: 176-185.

8. Lee YB, Lee HJ, Kang SK, Lee JY, Nam SY, Cheon SH, Sohn HS. Evaluation of the preventive effect of isoflavone extract on bone loss in ovariectomized rats. Biosci Biotechnol Biochem 2004; 68: 1040-1045.

9. Luthria $D L$, Biswas $R$, Natarajan $S$. Comparison of extraction solvents and techniques used for the assay of isoflavones from soybean. Food Chem 2007; 105: 325333.

10. Rostagno MA, Palma M, Barroso CG. Ultrasoundassisted extraction of soy isoflavones. Anal Chim Acta 2007; 588: 274-282.

11. Hua L, Hu G, Dan L, Hua L, Hu G, Dan L. Study of thermodynamic mechanism for using organic solvent to extract isoflavone from soybean residuals. Korean Chem Soc 2009; 53: 427-431.

12. Tang W, Xie $C$, Wang $Z$, Wu S, Feng $Y$, Wang $X$, Wang $J$, Gong J. Solubility of androstenedione in lower alcohol. Fluid Phase Equilib2014; 363: 86-96. 
13. Mu H, Bai YH, Wang ST, Zhu ZM, Zhang YW. Research on antioxidant effects and estrogenic effect of formononetin from Trifolium pratense (red clover). Phytomedicine 2009; 16: 314-319.

14. Singh VK, Pandey PM, Agarwal T, Kumar D, Banerjee I, Arfat A, Pal K. Development of soy lecithin based novel self-assembled emulsion hydrogels. J Mech Behav Biomed Mater 2015; 55: 250-263.

15. Zeisel SH, Da Costa KA, Franklin PD, Alexander EA, Lamont JT, Sheard NF, Beiser A. Choline: an essential nutrient for humans. Nutrition 2000; 16: 669-671.

16. Willimann HL, Luisi PL. Lecithin organogels as matrix for the transdermal transport of drugs. Biochem Biophys Res Commun 1991; 177: 897-900

17. Abbasi S, Radi M. Food grade microemulsion systems: canola oil/lecithin:n-propanol / water. Food Chem 2016; 194: 972-979.

18. Mehta SK, Jindal N. Mixed micelles of Lecithin-Tyloxapol as pharmaceutical nanocarriers for anti-tubercular drug delivery. Colloids Surf B: Biointerfaces 2013; 110: 419425.

19. Imran M, Revol-Junelles A, Paris C, Guedon E, Linder M, Desobry S. Liposomal nanodelivery systems using soy and marine lecithin to encapsulate food biopreservative nisin. LW-Food Sci Technol 2015; 62: 341-349.

20. Paini M, Daly SR, Aliakbarian B, Fathi A, Tehrany EA, Perego $P$, Dehgani $F$, Valtchev $P$. An efficient liposome based method for antioxidants encapsulation. Colloids Surf B: Biointerfaces 2015; 136: 1067-1072.

21. Pérez-Molina Al, Juarez-Ordaz AJ, Greogorio-Jauregui $K M$, Segura-Ceniceros EP, Martinez-Hernandez JL,
Rodriguez-Martinez J, llyina A. Thermodynamics of laminarinase partitioning in soya lecithin liposomes and their storage stability. J Mol Catal B: Enzym 2011; 72 : 65-72.

22. Rogerson ML, Robinson BH, Bucak S, Walde P. Kinetic studies of the interaction of fatty acids with phosphatidylcholine vesicles (liposomes). Colloids Surf B Biointerfaces2006; 48 : 24-34

23. Zhu ZY, Liu F, Gao $H$, Sun $H Q$, Meng M, Zhang YM. Synthesis, characterization and antioxidant activity of seleniumpolysaccharide from Cordyceps militaris. Int $\mathrm{J}$ Biol Macromol 2016; 99: 1090-1099.

24. Leeuwen SSV, Leeflang BR, Gerwig GJ, Kamerling JP. Development of a $1 \mathrm{H}$ NMR structural-reporter-group concept for the primary structural characterisation of $\alpha$ D-glucans. Carbohydr Res 2008; 343: 1114-1119.

25. Lai LS, Yang DH. Rheological properties of the hot-water extracted polysaccharides in Ling-Zhi (Ganoderma lucidum). Food Hydrocolloid 2007; 21: 739-746.

26. Zheng Y, Liu H, Bai YJ, Ma YM, Zhao YY. Five flavonoids from spatholobussuberectus. China J Chin Mater Med 2008; 33: 152-154.

27. Zhou SX, Yao ZR, Li J, Tu PF. Flavonoids from the leaves of Ilex cornuta. Chin J Nat Med 2012; 10: 0084-0087.

28. Wang J, Cao Y, Sun B, Wang C. Characterisation of inclusion complex of trans-ferulic acid and hydroxypropyl- $\beta$-cyclodextrin. Food Chem 2011; 124: 1069-1075. 